\title{
Community exercise is feasible for neuromuscular diseases and can improve aerobic capacity
}

Amanda Wallace, PhD, Aleksandra Pietrusz, BSc, Elizabeth Dewar, MSc, Magdalena Dudziec, BSc, Katherine Jones, PhD, Philip Hennis, PhD, Annette Sterr, PhD, Gianluca Baio, PhD,

Pedro M. Machado, MD, PhD, Matilde Laurá, MD, PhD, Iwona Skorupinska, BSc, Mariola Skorupinska, MSc, Karen Butcher, Michael Trenell, PhD, Mary M. Reilly, MD, Michael G. Hanna, BMBCh, MD, and Gita M. Ramdharry, PhD

Neurology ${ }^{\circledR}$ 2019;92:e1773-e1785. doi:10.1212/WNL.0000000000007265

\section{Abstract}

\section{Objective}

The aim of this phase 2 trial was to ascertain the feasibility and effect of community-based aerobic exercise training for people with 2 of the more common neuromuscular diseases: Charcot-Marie-Tooth disease type 1A (CMT) and inclusion body myositis (IBM).

\section{Methods}

A randomized single-blinded crossover trial design was used to compare a 12-week aerobic training program using recombinant exercise bicycles compared to a control period. The training occurred 3 times per week in community gyms local to the participants. Support was available from trained gym staff and a research physiotherapist. The 2 disease groups were analyzed separately. The primary outcome measure was peak oxygen uptake $\left(\mathrm{VO}_{2}\right.$ peak $)$ during a maximal exercise test, with secondary measures of muscle strength, function, and patientreported measures.

\section{Results}

Data from 23 people with CMT and 17 people with IBM were included in the analysis. Both disease groups had high levels of participation and demonstrated improvements in $\mathrm{VO}_{2}$ peak, with a moderate effect size in the CMT participants (Cohen $d=0.53$ ) and a strong effect size in the IBM group (Cohen $d=1.72$ ). No major changes were observed in the secondary outcome measures. Qualitative interviews revealed that participants valued the support of gym instructors and the research physiotherapists in overcoming challenges to participation.

\section{Conclusion}

Twelve weeks of aerobic training in community gyms was feasible, safe, and improved aerobic capacity in people with CMT and IBM.

\section{Classification of evidence}

This study provides Class II evidence that for patients with CMT type 1A and IBM, an aerobic training program increases aerobic capacity.

\author{
Correspondence \\ Dr. Ramdharry \\ g.ramdharry@ucl.ac.uk
}

\section{$\rightarrow$ Class of Evidence}

Criteria for rating therapeutic and diagnostic studies

NPub.org/coe 


\section{Glossary}

CK = creatine kinase; CMT = Charcot-Marie-Tooth disease type 1A; CMTES = CMT Examination Score; IBM = inclusion body myositis; IBMFRS = IBM Functional Rating Scale; NMD = neuromuscular disease; $\mathbf{W}=$ maximum work rate during the exercise testing.

This phase 2 feasibility trial aims to establish whether community-based aerobic training is safe, feasible, and can improve cardiopulmonary fitness in 2 more common neuromuscular diseases (NMDs): Charcot-Marie-Tooth disease type $1 \mathrm{~A}(\mathrm{CMT})$ and sporadic inclusion body myositis (IBM).

Aerobic deconditioning and secondary disuse muscle atrophy are common in people with NMD and are a likely consequence of reduced general activity levels. Investigations of people with CMT found they are less active than the general population ${ }^{1-3}$ and are deconditioned, as measured by oxygen uptake during exercise. ${ }^{4}$ Similar reductions in aerobic capacity have been reported in people with idiopathic inflammatory myopathy. ${ }^{5}$

Only 3 underpowered, uncontrolled studies have been conducted in these 2 conditions. ${ }^{6-8}$ These preliminary studies indicate positive benefits of aerobic training for people with CMT and IBM but there is a need for larger trials with comparison to a control. These early studies were undertaken in hospital environments with supervision by health professionals. For lifelong behavior change, taking exercise away from the hospital and into community gym facilities may be a step to encouraging self-management, supporting the transition from exercise as a medical intervention to a leisure activity. ${ }^{9}$ The feasibility of moving exercise interventions into leisure facilities is untested in these conditions.

There were 3 stated aims of this study: (1) calculate the effect of training on aerobic capacity; (2) ascertain whether supported aerobic training in community leisure facilities is feasible, safe, and acceptable; (3) explore secondary physical and nonphysical effects of exercise.

\section{Methods}

\section{Design}

We used a single-blinded crossover design to explore the effect and feasibility of aerobic exercise training in the community. This design was used in response to observations in the field that participants are more likely to stay in a study if they receive treatment. ${ }^{10}$ These rare diseases are challenging to recruit, so strategies to retain participants, and reduce the effect of intersubject variation in smaller samples, were key factors in this choice of design. We have prior experience of conducting crossover exercise trials. ${ }^{11}$

Participants were randomized to 2 groups. Group A underwent a 12-week training period (T1), an 8-week reversal period to detrain, then a 12-week control period (C2). Group $\mathrm{B}$ went through the control period first $(\mathrm{C} 1)$ and the training period second (T2). We decided to also include an 8-week period between $\mathrm{C} 1$ and $\mathrm{T} 2$ for group $\mathrm{B}$ to maintain blinding of assessors. People with metabolic syndrome detrain within in 1-2 months, ${ }^{12}$ older men detrain to baseline in 4 weeks, ${ }^{13}$ and people with mitochondrial disease return to baseline aerobic fitness after 8 weeks. ${ }^{14}$ From this evidence, 8 weeks was deemed sufficient for the detraining period.

Four assessments were undertaken by blinded assessors to measure outcomes before and after the treatment and control periods. It was not possible to blind participants in an exercise trial where aerobic capacity testing was performed using a bicycle ergometer, similar to the training intervention.

Participants from both disease groups were recruited and partook in the trial concurrently, but data were analyzed separately.

\section{Sample size estimate}

The primary purpose of this study was to explore effect on aerobic capacity and feasibility of training, but an estimated sample size was calculated combining evidence from similar studies $^{7,8}$ and our own experience. We estimated an intrasubject coefficient of variation of 0.2 , which translates into $\mathrm{VO}_{2}$ measurements outside the range $17-40 \mathrm{~mL} / \mathrm{min} / \mathrm{kg}$ being extremely unlikely. Using the approach based on 2 one-sided hypothesis tests for a $2 \times 2$ crossover trial, a total sample size of 20 participants gave at least $80 \%$ power to detect an effect of up to 1.06 in the ratio of mean $\mathrm{VO}_{2}$ under the treatment and the control regimes. To account for dropouts, the target sample size was set at 30 ( 15 in each treatment sequence) in 2 parallel studies (one for each condition) with 30 participants each.

\section{Standard protocol approvals, registrations, and patient consents}

This study achieved NHS NRES ethical approval (ref: 11/ LO/0760) and consent for participation was obtained, recorded, and filed. This study was registered on the ISRCTN clinical trials registry (ID: 99826269)

\section{Recruitment strategy}

Potential participants were recruited from clinics and research databases of the National Hospital for Neurology and Neurosurgery, plus national clinics of colleagues from the British Myology Society for people with IBM.

Participants were included in the study if they met the following criteria: clinical and genetic diagnosis of CMT type 1A, or a clinical diagnosis of IBM, supported by histologic confirmation as per the established Griggs criteria (only Griggs definite IBM cases were included); aged 18-80; able to walk 
for 30 meters with or without a walking aid or orthotic devices; ability to safely mount/dismount an exercise bike unaided or with minimal assistance; and signed informed participant consent.

Exclusion criteria were presence of other significant neurologic disorders or major comorbidities; limb surgery during the 6 months prior to screening (or planned before final assessment); failure to pass the screening assessment for exercise testing; aged over 80 or under 18 years; concurrent involvement in another intervention trial; people already participating in moderate to vigorous aerobic exercise more than 3 times per week; and women of childbearing age if they were pregnant or planning to become pregnant during the study.

\section{Randomization}

A block randomization method was used to allocate participants to groups. Block sizes of 4 were used based on random numbers generated in MATLAB (Mathworks, Cambridge, UK). The random block sequences were stored on a password-protected spreadsheet. Allocation to the groups was input and spreadsheets held by an unblinded member of staff who were not involved in screening, recruitment, assessment, or training of the participants. This ensured allocation was concealed after enrollment and consent. Allocation was stratified according to baseline disease severity scores. For the Charcot-Marie-Tooth Neuropathy Score, categories were mild (0-10), moderate (11-20), and severe (over 20). For the IBM, the IBM Functional Rating Scale (IBMFRS) categories were mild (over 28), moderate (14-28), and severe $(0-14) \cdot{ }^{15,16}$

\section{Intervention}

There are no specific guidelines for exercise training in neuromuscular diseases and therefore we adapted the aerobic training protocols recommended by the American College of Sports Medicine, considered gold standard for aerobic exercise to maintain health and fitness. ${ }^{17}$ We also used previous protocols used in other neuromuscular exercise studies, some of which were developed by our team. ${ }^{14}$

Participants trained in their local gyms for convenience and to increase participation. Weekly sessions with professionally qualified fitness instructors were arranged for the first month, then every other week for the second and third months. Fitness instructors received face-to-face training in the intervention protocol by the research physiotherapist, and received a training manual. The research physiotherapist visited the gym at the beginning and midpoint of the training period, and conducted a telephone review every 2 weeks. Extra calls or visits were made where either the participant or the fitness instructor identified a need for more support.

Participants exercised on a bicycle ergometer 3 times per week for 12 weeks (36 sessions) working towards a duration of 30 minutes. All had heart rate monitors to set training targets. Initially the target heart rate corresponded to $60 \%$ of $\mathrm{VO}_{2}$ peak. The intensity was progressively increased to $70 \%$ after 4 weeks and $80 \%$ after 8 weeks. Target heart rates were calculated using the standard formula: 220 minus the participant's age. We found in some weaker participants that they struggled to meet the heart rate training levels. In these cases, we used the BORG perceived exertion ratings to ensure they were training at a sufficiently high intensity.

Each exercise session began with a 5-minute warm-up on the bicycle ergometer and ended with a 5- to 10-minute cool-down period. Participants were encouraged to exercise on alternative days to allow time for recovery and reduce general orthopedic stress. ${ }^{17}$ Exercise participation and symptoms such as fatigue, pain, and mood were recorded using an exercise diary. Diary completion was monitored by the research physiotherapist during fortnightly phone calls and a midway gym visit.

For the control and detraining period, participants were asked to continue their normal, prestudy activity levels. They continued to complete the exercise diary and were encouraged to complete any additional exercise or activity they had done. Participants had a monthly telephone review during the control period where general activity, fatigue, pain, and mood were recorded.

\section{Primary outcome}

The primary outcome measure was maximum aerobic capacity measured as peak oxygen uptake $\left(\mathrm{VO}_{2}\right.$ peak) during a symptom-limited progressive exercise test on a semirecombinant bicycle ergometer. Oxygen uptake was measured using indirect calorimetry (Cortex Metalyzer, Biophysik, Leipzig, Germany).

Prior to undertaking a maximal exercise test, participants underwent screening to ensure there was no evidence of cardiac dysfunction and therefore minimal risk of cardiac events during the protocol. ECG and blood pressure were monitored before, during, and after the test.

\section{Secondary outcomes}

A battery of body structure and function, impairment, activity, and self-reported measures was used to ascertain additional effects of the aerobic training. Body structure and function measures were as follows: body mass index (BMI) and percentage body fat, measured using skin fold calipers; blood pressure and lung function (hand-held spirometry); fatigue severity using the Fatigue Severity Scale; pain, using a visual analogue scale; and isometric and isokinetic lower limb muscle function, using Cybex HUMAC dynamometer. Activity measures were maximum work rate during the exercise testing (W); 10-meter timed walk; 6-minute walk distance; and perceived walking function using the Walk-12 scale plus physical activity measured using Sensewear activity monitors for 1 week at the start of the trial and 1 week at the end of the training phase. Disease-specific measures were used to ascertain impairment and disability: CMT Examination Score (CMTES) for participants with CMT and the IBMFRS for participants with IBM. Other measures were self-efficacy for 
managing chronic diseases (6-item scale); barriers to activity and exercise; Short Form-36 quality of life measure; Pittsburgh Sleep Quality Scale; Epworth Sleepiness Scale; and International Physical Activity Questionnaire.

\section{Safety monitoring}

During the training and control periods, participants recorded pain and fatigue levels using visual analogue scales. This was monitored by the research team during telephone reviews and the measurement sessions. Blood creatine kinase levels were recorded at each of the measurement sessions to monitor any change that could be indicative of muscle damage.

\section{Statistical analysis}

The main analysis was descriptive as this phase 2 exploratory study was not powered for efficacy, and the size of effect was calculated for the primary outcome only. Means and SDs were calculated for continuous and interval data, with medians and interquartile ranges used for categorical measures. Missing data postintervention were imputed using a missing at random assumption. Where preintervention primary outcome data were missing (e.g., if participants were unable to undergo exercise testing due to raised blood pressure), the data for that individual were not included in the effect size analysis. We calculated the size of the effect of training on $\mathrm{VO}_{2}$ peak using both the Cohen $d$ and Hedges $g$ statistics, to account for any clustering within individuals. Data for participants who withdrew partway through the study were included for the time points prior to their exit.

\section{Qualitative analysis}

Study participants were invited for a semi-structured telephone interview once they had completed the final assessment. The interviewer was not part of the main intervention team and was unknown to the participant (A.S.). Questions centered on attitudes to exercise, experience of being in the trial, and how the training intervention affected the participant. The interview was digitally recorded, transcribed, and coded using thematic analysis for emerging themes.

\section{Post-trial follow-up}

All participants were telephoned by the research physiotherapist 3 months after the cessation of the study to see if they were continuing to exercise.

\section{Data availability}

Any data not published within the article will be shared in an anonymized format, by request from any qualified investigator.

Figure 1 Consolidated Standards of Reporting Trials diagram
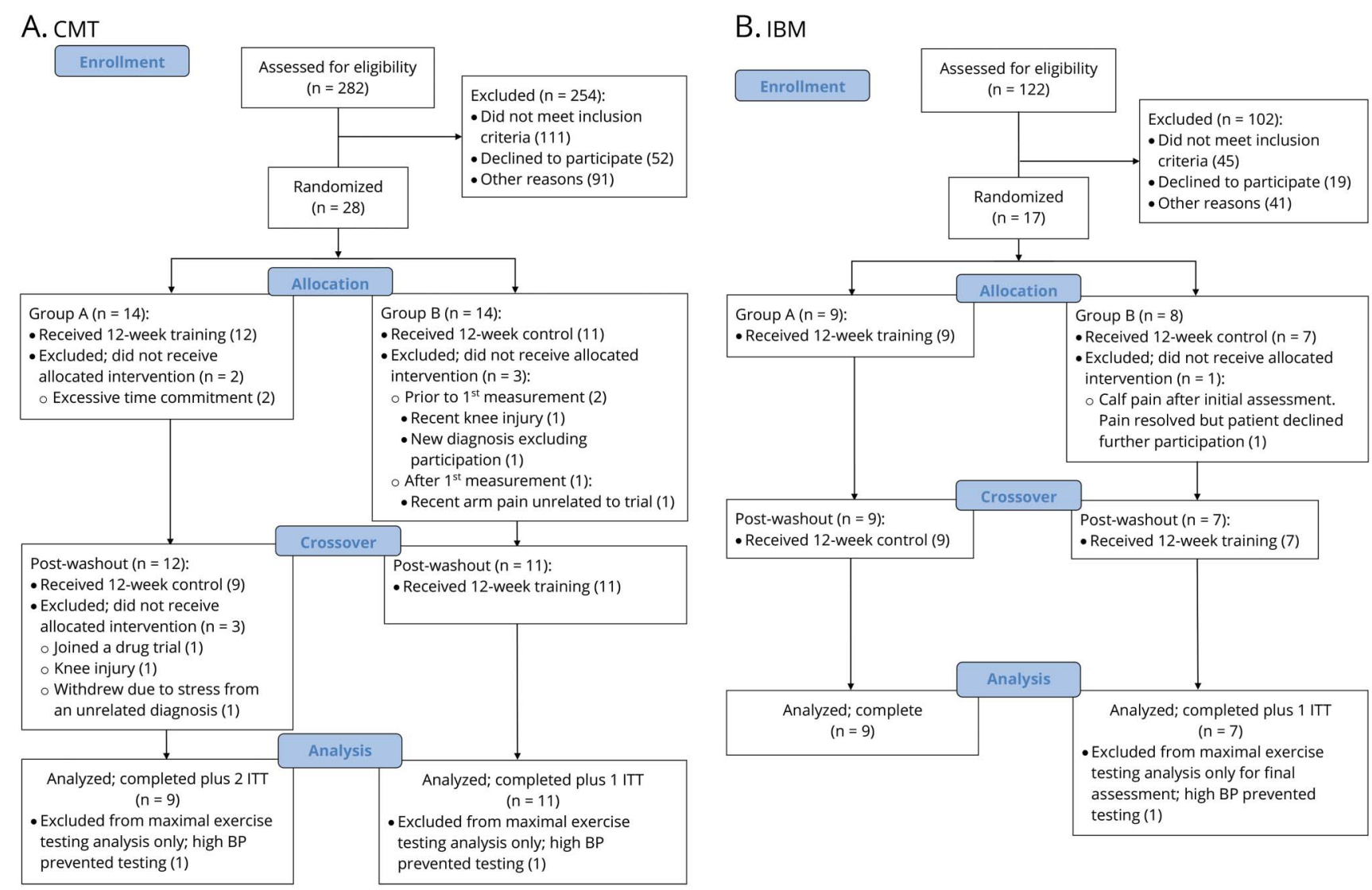

Recruitment, enrollment, allocation, and retention details of participants for the (A) (CMT) and (B) (IBM) groups. BP = blood pressure; ITT = intent-to-treat. 


\section{Classification of evidence}

This intervention study provides Class II evidence for the primary research question: What is the effect of communitybased aerobic exercise training (for 12 weeks, 3 times a week at $80 \%$ of maximum heart rate) on aerobic capacity in people with CMT and IBM?

For the secondary aims, this study provides Class II evidence for the second research question: Is the intervention safe and acceptable? It also provides Class III evidence for the third research question: Are there effects on physical function, lower limb strength, fatigue, sleep, physical and quality of life?

\section{Results}

\section{Recruitment}

The recruitment target for the CMT group was 30 people over a 26-month period. In total, 282 people with CMT were invited to participate and 254 were excluded, refused, or did not respond. The most common reasons for active exclusion were coexisting illness or recent limb surgery (60), already exercising over 3 days per week (32), or unable to meet time commitments (27). Thirty-one people underwent more detailed screening but 3 failed to meet the study criteria. A total of 28 people with CMT enrolled during the study period, giving a recruitment rate of 1.1 per month. Of these 28 people, 5 withdrew before starting ( 2 due to time commitments, 2 due to an unrelated injuries, and 1 due to a new cardiac diagnosis) and 3 partway through the study ( 1 joined a drug trial, 1 knee injury, 1 due to stress). In total, 20 people fully completed the study protocol, but the data for the 23 people who started the study were used for analysis using an intention-to-treat approach (figure 1).

The recruitment target for the IBM group was 30 people over a 26-month period. In total, 122 people with IBM were invited to participate and 102 were unable to commit to the trial or did not meet the study criteria on initial screening. The most common reasons were as follows: too old for the age criteria (27); did not want to participate (19); coexisting illness (18). A total of 20 people with IBM enrolled during the study period, giving a recruitment rate of 0.9 per month. Of these 20 people, 3 withdrew before being randomized ( 2 due to preexisting conditions, 1 was put off by the control period) and 1 withdrew part way through. In total, 16 people fully completed the study protocol, but the data for the 17 people who started the study were used for analysis using an intention-totreat approach (figure 1).

\section{Participant characteristics}

The CMT group was significantly younger than the IBM group, and both groups were mildly overweight, according to the mean BMI (table 1). The proportion of male to female participants was $58 \%$ male in the CMT group and $81 \%$ male in the IBM group. Both groups were moderately affected by their condition, according to the CMTES for the CMT group and IBMFRS for the IBM group (table 1).

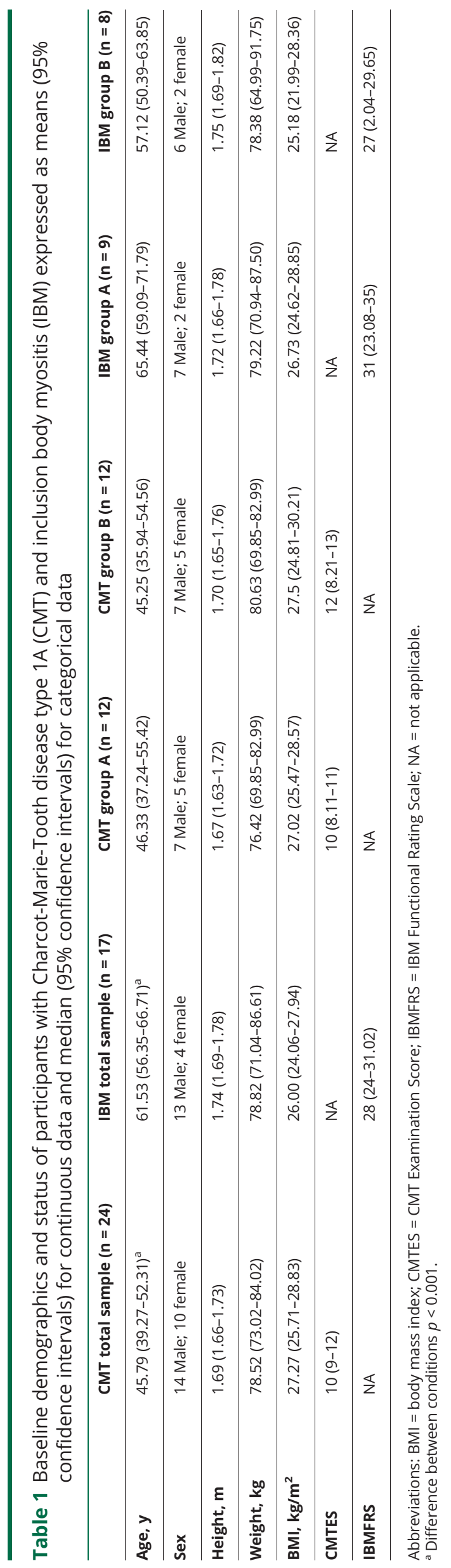


Table 2 Outcome measures for Charcot-Marie-Tooth disease type 1A participants, group A and B, at the 4 measurement timepoints

\begin{tabular}{|c|c|c|c|c|c|c|c|c|}
\hline & \multicolumn{4}{|l|}{ Group A } & \multicolumn{4}{|l|}{ Group B } \\
\hline & Pre-training & Post-training & Pre-control & Post-control & Pre-control & Post-control & Pre-training & Post-training \\
\hline $\mathrm{VO}_{2}$ peak, $\mathrm{mL} / \mathrm{min} / \mathrm{kg}$ & $22.09 \pm 4.32$ & $24.91 \pm 3.88$ & $25.14 \pm 4.98$ & $23.63 \pm 4.03$ & $21.09 \pm 5.03$ & $22.40 \pm 4.50$ & $22.50 \pm 4.77$ & $24.10 \pm 5.09$ \\
\hline Workload, w & $136.36 \pm 41.19$ & $153.27 \pm 30.72$ & $148.43 \pm 27.07$ & $147.25 \pm 19.70$ & $127.72 \pm 43.91$ & $134.40 \pm 40.12$ & $139.00 \pm 46.20$ & $151.00 \pm 50.97$ \\
\hline CMTES & $10(2.5)$ & $10.5(5.5)$ & $10(6)$ & $11(2)$ & $12(2)$ & $12(7)$ & $12(5)$ & $12(6)$ \\
\hline $\mathrm{BMI}, \mathrm{kg} / \mathrm{m}^{2}$ & $27.03 \pm 2.66$ & $27.22 \pm 2.42$ & $27.23 \pm 2.37$ & $27.55 \pm 2.69$ & $27.51 \pm 4.62$ & $27.06 \pm 4.15$ & $26.95 \pm 4.35$ & $26.92 \pm 4.21$ \\
\hline Body fat $\%$ & $24.35 \pm 4.82$ & $25.05 \pm 4.99$ & $25.62 \pm 4.89$ & $25.86 \pm 4.68$ & $26.00 \pm 6.42$ & 25.314 .05 & $26.55 \pm 4.71$ & $26.01 \pm 4.72$ \\
\hline Systolic BP, mm Hg & $127.33 \pm 22.14$ & $125.92 \pm 22.57$ & $126.33 \pm 25$ & $124.78 \pm 21.19$ & $124.92 \pm 21.28$ & $122.91 \pm 18.55$ & $126.82 \pm 14.59$ & $125.36 \pm 19.78$ \\
\hline Diastolic BP, mm Hg & $78.00 \pm 6.74$ & $79.33 \pm 5.22$ & $74.89 \pm 3.82$ & $78.00 \pm 5.94$ & $78.33 \pm 6.29$ & $77.45 \pm 6.20$ & $79.82 \pm 7.32$ & $76.36 \pm 7.00$ \\
\hline FVC, L & $3.14 \pm 0.77$ & $3.21 \pm 0.77$ & $3.13 \pm 0.64$ & $3.14 \pm 0.73$ & $3.31 \pm 0.96$ & $3.33 \pm 1.06$ & $3.47 \pm 1.01$ & $3.49 \pm 0.96$ \\
\hline Fatigue severity (FSS) & $33(22.5)$ & $28(16.5)$ & $20(27)$ & $27(20)$ & $32(18.5)$ & $25(18)$ & $29(17)$ & $25(18)$ \\
\hline Pain VAS & $2(5.5)$ & $0.5(5.5)$ & $2(5)$ & $0(3)$ & $3(4)$ & $1(4)$ & $0(3)$ & $0(1)$ \\
\hline Isometric extensor torque $45^{\circ}, \mathrm{Nm}$ & $112.21 \pm 45.67$ & $121.29 \pm 36.70$ & $116.61 \pm 34.51$ & $116.83 \pm 38.47$ & $102.88 \pm 46.36$ & $111.77 \pm 50.40$ & $114.18 \pm 54.00$ & $114.68 \pm 59.23$ \\
\hline Isometric extensor torque $90^{\circ}, \mathrm{Nm}$ & $121.42 \pm 52.35$ & $118.96 \pm 46.65$ & $117.39 \pm 53.33$ & $115.22 \pm 52.22$ & $103.92 \pm 52.60$ & $88.45 \pm 58.30$ & $101.95 \pm 58.81$ & $101.23 \pm 59.60$ \\
\hline Isometric flexor torque $45^{\circ}, \mathrm{Nm}$ & $65.13 \pm 26.74$ & $67.75 \pm 20.80$ & $64.94 \pm 18.90$ & $61.28 \pm 17.39$ & $62.67 \pm 25.81$ & $66.18 \pm 32.42$ & $67.82 \pm 32.57$ & $68.50 \pm 34.14$ \\
\hline Isokinetic peak extensor torque $30^{\circ} / \mathrm{s}, \mathrm{Nm}$ & $95.96 \pm 33.49$ & $103.92 \pm 29.38$ & $95.89 \pm 32.70$ & $97.89 \pm 33.88$ & $98.04 \pm 52.60$ & $99.54 \pm 53.84$ & $98.32 \pm 56.20$ & $98.73 \pm 57.16$ \\
\hline Isokinetic peak flexor torque $30 \% / \mathrm{s}, \mathrm{Nm}$ & $49.75 \pm 17.24$ & $56.54 \pm 15.01$ & $50.78 \pm 11.71$ & $49.89 \pm 12.41$ & $55.71 \pm 25.98$ & $57.59 \pm 26.83$ & $57.35 \pm 27.68$ & $61.32 \pm 28.68$ \\
\hline 10-m timed walk: self-paced, s & $10.18 \pm 1.84$ & $9.19 \pm 1.23$ & $8.69 \pm 0.77$ & $8.61 \pm 0.85$ & $9.97 \pm 2.17$ & $9.48 \pm 2.30$ & $9.75 \pm 2.04$ & $9.28 \pm 1.91$ \\
\hline 10-m timed walk: maximum speed, s & $7.67 \pm 1.92$ & $7.24 \pm 1.46$ & $6.81 \pm 0.80$ & $6.81 \pm 0.94$ & $7.31 \pm 1.61$ & $7.32 \pm 1.79$ & $7.43 \pm 1.81$ & $8.39 \pm 3.62$ \\
\hline 6-min walk distance, $\mathrm{m}$ & $375.83 \pm 81.17$ & $406.00 \pm 75.06$ & $423.55 \pm 59.28$ & $423.17 \pm 58.46$ & $362.14 \pm 87.48$ & $380.227 \pm 91.52$ & $381.77 \pm 85.19$ & $393.95 \pm 87.04$ \\
\hline Walk-12 & $38.5(11)$ & $37.5(15.5)$ & $38(16)$ & $35(15)$ & $34.5(11.5)$ & $34(20)$ & $34(16)$ & $35(13)$ \\
\hline IPAQ sit time, min & $300(165)$ & $240(180)$ & $360(300)$ & $330(330)$ & $420(165)$ & $390(180)$ & $450(240)$ & $420(300)$ \\
\hline Barriers to activity and exercise & $3.5(5)$ & $4.5(4.5)$ & 4() & $3(6)$ & $4(2)$ & $4(2)$ & $4(6)$ & $5(4)$ \\
\hline Self-efficacy scale & $38(18)$ & $45(22)$ & $45(25)$ & $43(21)$ & $42(19.5)$ & $43(17)$ & $45(17)$ & $46(15)$ \\
\hline SF-36 & $96(8.5)$ & $96.5(8.5)$ & $94(8)$ & $93(8)$ & $101(9)$ & $104(10)$ & $100(7)$ & $98(8)$ \\
\hline
\end{tabular}




\section{Participation in training intervention}

The training diaries revealed that the CMT group participated in $76 \%$ of total training sessions, and the IBM group completed $91 \%$ of sessions.

\section{Primary outcome}

In the CMT group, the differences with training and control periods for groups $A$ and $B$ are detailed in table 2 and figure $2 \mathrm{~A}$. When the training and control data for both groups were combined, there was an $11.7 \%$ improvement in $\mathrm{VO}_{2}$ peak with training (pre-training $22.00 \mathrm{~mL} / \mathrm{min} / \mathrm{kg}$, post-training $24.52 \mathrm{~mL} / \mathrm{min} / \mathrm{kg}$ ) compared to a $0.1 \%$ deterioration with the control period (precontrol $23.06 \mathrm{~mL} / \mathrm{min} / \mathrm{kg}$, post-control $22.94 \mathrm{~mL} / \mathrm{min} / \mathrm{kg}$ ). The Cohen $d$ and the Hedges $g$ calculations for change in $\mathrm{VO}_{2}$ peak showed moderate treatment effect sizes.

In the IBM group, differences for each group are detailed in table 3 and figure $2 \mathrm{~B}$. Combining the training and control data for both groups showed a $17.4 \%$ improvement in $\mathrm{VO}_{2}$ peak with training (pre-training $14.00 \mathrm{~mL} / \mathrm{min} / \mathrm{kg}$, post-training $16.44 \mathrm{~mL} / \mathrm{min} / \mathrm{kg}$ ) compared to a $1.3 \%$ deterioration with the control period (pre-control $14.94 \mathrm{~mL} / \mathrm{min} / \mathrm{kg}$, post-control $14.75 \mathrm{~mL} / \mathrm{min} / \mathrm{kg}$ ). The effect sizes for training vs no-training were strong (table 4$)$.

\section{Secondary outcomes}

In the CMT group, when the training and control data for both groups are combined, there was a $13.1 \%$ improvement in work rate with training (pre-training $137.62 \mathrm{~W}$, post-training $152.19 \mathrm{~W}$ ) compared to a $1.5 \%$ improvement with the control period (pre-control $135.78 \mathrm{~W}$, post-control $140.11 \mathrm{~W}$ ). Differences between the 2 groups are detailed in table 2 and figure $2 \mathrm{C}$. The IBM group also demonstrated changes in work rate when group data was combined. They had a $17.3 \% \mathrm{im}-$ provement with training (pre-training 59.87, post-training $70.25 \mathrm{~W}$ ) compared to a $0.4 \%$ improvement with the control period (pre-control 63.00, post-control 63.25 W). Differences between the 2 groups are detailed in table 3 and figure 2D.

There were no major differences with training observed in the other secondary measures for the CMT and IBM participants (tables 2 and 3). A notable challenge when using the isokinetic dynamometer for very weak muscles, particularly the quadriceps muscles for the patients with IBM, was the difficulty some participants found in generating sufficient torque to trigger the motor. This may have affected the reliability of the dynamometry data.

Activity monitors administered for 7 days at the start and end of the trial showed no changes in physical activity duration over 3 metabolic equivalent tasks (CMT: pre-trial 2,490 \pm 492 minutes, post-trial 2,390 \pm 417 ; IBM: pre-trial 2,336 \pm 480 minutes, posttrial $2,420 \pm 424$ ) or other physical activity variables.

\section{Safety monitoring}

There were no increases in serum creatine kinase $(\mathrm{CK})$ at group or individual level with exercise training in both 

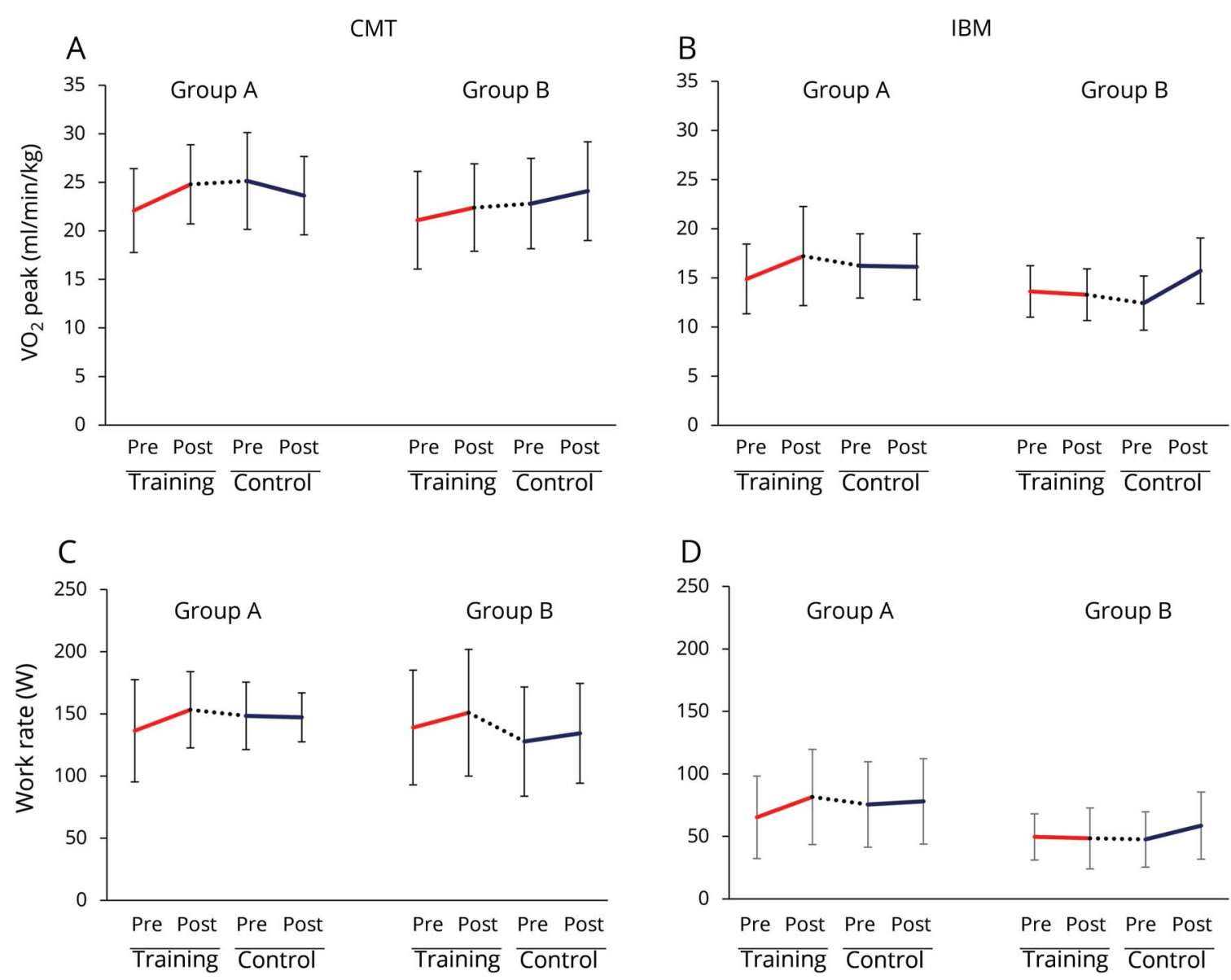

Line graphs of mean $\mathrm{VO}_{2}$ peak ( $\mathrm{mL} / \mathrm{min} / \mathrm{kg}$ ) for the Charcot-Marie-Tooth disease type $1 \mathrm{~A}(\mathrm{CMT})$ group (A); $\mathrm{VO}_{2}$ peak for the inclusion body myositis (IBM) group (B); work rate (W) for the CMT group (C); work rate for the IBM group (D). Error bars are SD, solid lines represent change with the 12-week intervention/control periods, dotted lines represent change during the 8-week reversal period at crossover.

conditions. There were also no changes in energy, mood, or fatigue as recorded via the visual analogue scales in the training diaries.

\section{Continuation of training}

All participants were contacted by telephone 3 months after the trial. Contact was successfully made with 16 of the CMT participants. Eight of the 16 were still exercising, but of those who had stopped, time and work commitments were the most common reason given. Twelve participants with IBM were successfully contacted. Only 5 of the 12 were still exercising. Of the 7 who had stopped, various reasons were given, such as gym expense and access, lost confidence, time pressures, and one case of an injurious fall.

\section{Qualitative results}

A total of 46 participants agreed to be interviewed following the trial, 32 with CMT and 14 with IBM. The experiences were common to both conditions and the following themes were identified from the data: reasons for participating in the trial; expectations; experience of participating in the trial; support; outcomes of exercise (table 5). Participants took part for altruistic and personal reasons, with the expectation that they would benefit. They expected improvements from participating in exercise and found participation in the trial acceptable. Some participants experienced physical challenges and stressed the importance of the gym instructors and research team. Overall, they described positive outcomes of the exercise intervention and expressed a desire to continue exercising, though stated that gym membership costs could be a barrier.

\section{Discussion}

It was encouraging that delivering community-based aerobic training in leisure-based exercise facilities was achievable. The excellent participation rates indicate that the approach is feasible for people with CMT and IBM; however, the low rate of continuation following the study, compared to a review of follow-up participation in other disabilities, ${ }^{18}$ indicates that self-motivation alone may not be sufficient for people with NMDs to continue independently. The qualitative findings indicated that support of health or exercise professionals and 


\begin{tabular}{|c|c|c|c|c|c|c|c|c|}
\hline & \multicolumn{4}{|l|}{ Group A } & \multicolumn{4}{|l|}{ Group B } \\
\hline & Pre-training & Post-training & Pre-control & Post-control & Pre-control & Post-control & Pre-training & Post-training \\
\hline $\mathrm{VO}_{2}$ peak, $\mathrm{mL} / \mathrm{min} / \mathrm{kg}$ & $15.38 \pm 3.46$ & $17.00 \pm 5.29$ & $16.11 \pm 3.37$ & $15.89 \pm 3.22$ & $13.63 \pm 2.62$ & $13.29 \pm 2.63$ & $12.43 \pm 2.76$ & $15.71 \pm 3.35$ \\
\hline Workload (W) & $70.63 \pm 30.97$ & $79.33 \pm 41.06$ & $74.89 \pm 34.85$ & $74.78 \pm 33.45$ & $49.63 \pm 18.47$ & $48.43 \pm 24.32$ & $47.57 \pm 22.20$ & $58.87 \pm 26.89$ \\
\hline IBMFRS & $31(11)$ & $30(10)$ & $30(10)$ & $30(9)$ & $27(5.5)$ & $25(10)$ & $25(11)$ & $25(11)$ \\
\hline $\mathrm{BMI}, \mathrm{kg} / \mathrm{m}^{2}$ & $26.73 \pm 3.14$ & $26.54 \pm 3.41$ & $26.67 \pm 3.60$ & $26.56 \pm 3.71$ & $25.18 \pm 4.45$ & $26.41 \pm 3.08$ & $26.34 \pm 3.09$ & $26.23 \pm 3.25$ \\
\hline Body fat $\%$ & $23.38 \pm 5.85$ & $22.20 \pm 5.54$ & $22.27 \pm 5.48$ & $22.81 \pm 6.23$ & $25.41 \pm 2.98$ & $26.67 \pm 2.27$ & $26.05 \pm 2.16$ & $25.53 \pm 1.52$ \\
\hline Systolic BP, mm Hg & $137.78 \pm 12.36$ & $132.67 \pm 12.61$ & $125.78 \pm 16.78$ & $134.00 \pm 16.56$ & $125.58 \pm 11.49$ & $121.29 \pm 10.84$ & $123.00 \pm 10.44$ & $125.86 \pm 11.96$ \\
\hline Diastolic BP, mm Hg & $78.89 \pm 4.73$ & $80.11 \pm 8.65$ & $76.67 \pm 10.81$ & $77.38 \pm 6.28$ & $78.00 \pm 6.55$ & $76.71 \pm 7.34$ & $79.57 \pm 6.50$ & $79.43 \pm 3.69$ \\
\hline FVC, L & $2.96 \pm 0.99$ & $2.83 \pm 1.01$ & $2.94 \pm 0.94$ & $3.08 \pm 1.01$ & $2.81 \pm 0.88$ & $3.17 \pm 0.95$ & $3.20 \pm 0.85$ & $3.12 \pm 0.82$ \\
\hline Fatigue severity (FSS) & 29 ( 29$)$ & $31(11)$ & $30(19)$ & $28(12)$ & $30(21)$ & $29(18)$ & $30(25)$ & $29(26)$ \\
\hline Pain VAS (average day) & $1(2)$ & $0(3)$ & $0(4)$ & $0(2)$ & $1.5(3)$ & $1(4)$ & $1(3)$ & $1(3)$ \\
\hline Isometric extensor torque $45^{\circ}, \mathrm{Nm}$ & $39.77 \pm 46.18$ & $38.78 \pm 41.90$ & $35.11 \pm 37.72$ & $35.72 \pm 41.45$ & $17.56 \pm 23.55$ & $15.43 \pm 20.48$ & $16.57 \pm 21.62$ & $15.71 \pm 20.42$ \\
\hline Isometric extensor torque $90^{\circ}, \mathrm{Nm}$ & $36.77 \pm 36.62$ & $40.56 \pm 40.48$ & $41.33 \pm 46.72$ & $40.17 \pm 52.05$ & $15.13 \pm 11.78$ & $15.00 \pm 12.88$ & $15.21 \pm 13.02$ & $15.71 \pm 13.15$ \\
\hline Isometric flexor torque $45^{\circ}, \mathrm{Nm}$ & $54.61 \pm 31.93$ & $55.83 \pm 28.19$ & $57.72 \pm 30.94$ & $58.44 \pm 31.87$ & $35.25 \pm 11.07$ & $34.36 \pm 10.49$ & $36.29 \pm 13.66$ & $35.14 \pm 14.51$ \\
\hline Isokinetic peak extensor torque $30^{\circ} / \mathrm{s}, \mathrm{Nm}$ & $33.39 \pm 33.66$ & $36.33 \pm 36.55$ & $37.83 \pm 37.07$ & $33.94 \pm 41.13$ & $16.34 \pm 13.50$ & $15.21 \pm 10.71$ & $15.07 \pm 11.79$ & $15.07 \pm 11.96$ \\
\hline Isokinetic peak flexor torque $30 \% \mathrm{~s}, \mathrm{Nm}$ & $35.67 \pm 26.36$ & $38.33 \pm 24.40$ & $44.11 \pm 28.13$ & $42.83 \pm 29.79$ & $22.69 \pm 8.99$ & $22.93 \pm 10.86$ & $20.78 \pm 10.33$ & $19.5 \pm 10.88$ \\
\hline 10-m timed walk: self-paced, s & $11.31 \pm 3.52$ & $10.98 \pm 4.05$ & $10.37 \pm 3.28$ & $13.44 \pm 3.09$ & $13.52 \pm 3.53$ & $13.27 \pm 4.13$ & $13.04 \pm 2.96$ & $13.28 \pm 3.97$ \\
\hline 10-m timed walk: maximum speed, s & $9.40 \pm 3.94$ & $8.84 \pm 3.43$ & $8.62 \pm 3.15$ & $8.80 \pm 3.41$ & $11.17 \pm 3.22$ & $11.19 \pm 3.33$ & $13.94 \pm 2.39$ & $10.67 \pm 3.01$ \\
\hline 6-min walk distance, $\mathrm{m}$ & $327.42 \pm 92.04$ & $334.33 \pm 86.80$ & $338.95 \pm 79.96$ & $336.13 \pm 84.79$ & $252.22 \pm 67.38$ & $260.86 \pm 83.55$ & $270.29 \pm 77.80$ & $258.93 \pm 66.73$ \\
\hline Walk-12 & $41(14)$ & 39 ( 13) & $39(11)$ & $39(11)$ & $44(10)$ & $39(12)$ & $40(15)$ & $37(14)$ \\
\hline IPAQ sit time, min & $300(300)$ & 360 ( 180_) & $285(60)$ & $420(360)$ & $420(270)$ & $420(360)$ & $420(480)$ & $360(420)$ \\
\hline Barriers to activity and exercise & $2(2)$ & $2(2)$ & $3(1)$ & $1(1)$ & $3.5(5.5)$ & $3(6)$ & $4(4)$ & $0(5)$ \\
\hline Self-efficacy scale & $41(11)$ & $40(16)$ & $49(17)$ & $41(15)$ & $48(15)$ & $47(10)$ & $47(19)$ & $46(12)$ \\
\hline SF-36 & $97(15)$ & $92(8)$ & $95(9)$ & $93(10)$ & $90.5(9.5$ & $90(10)$ & $93(6)$ & $92(8)$ \\
\hline \multirow[t]{2}{*}{ Pittsburgh Sleep Quality Scale } & $6(4)$ & $7(7)$ & $8(5)$ & $8(6)$ & $5.5(3.5)$ & $6(6)$ & $5(5)$ & $5(5)$ \\
\hline & & & & & & & & Continued \\
\hline
\end{tabular}


Table 4 Summary of effect size statistics for the effect of aerobic training on $\mathrm{VO}_{2}$ peak compared to the control condition for the 2 disease groups

\begin{tabular}{cccccc}
\hline & Mean & SD & $\mathbf{2 . 5 \%}$ & Median (50\%) & $\mathbf{9 7 . 5 \%}$ \\
\hline CMT group & & & & & \\
\hline Cohen $\boldsymbol{d}$ & 0.53 & 0.28 & -0.025 & 0.53 & 1.10 \\
\hline Hedges $\boldsymbol{g}$ & 0.52 & 0.28 & -0.025 & 0.51 & 1.08 \\
\hline IBM group & & & & & \\
\hline Cohen $\boldsymbol{d}$ & 1.72 & 0.43 & 0.89 & 1.73 & 2.64 \\
\hline Hedges $\boldsymbol{g}$ & 1.68 & 0.42 & 0.87 & 1.68 & 2.57 \\
\hline
\end{tabular}

Abbreviations: $\mathrm{CMT}=$ Charcot-Marie-Tooth disease type 1A; IBM = inclusion body myositis.

free or low-cost gym membership could be key factors in longer term participation in exercise. This has also been suggested from exercise trials in other neurologic conditions. ${ }^{19-21}$ Safety of exercise has been questioned in NMDs previously, so the lack of change in serum CK levels, pain, or fatigue is reassuring.

Both disease groups showed improvement with aerobic training, with a particularly strong effect of training in the IBM group. This group was more deconditioned at baseline and may have had greater potential for improvement, plus they showed better adherence to the study protocol. Both disease groups showed better effect sizes than training trials in other neurologic diseases. ${ }^{22,23}$ The effect sizes are compelling despite not meeting target recruitment for analysis in the IBM group. It is worth noting that a priori, there was an underestimation of the intrasubject coefficient of variation of 0.2 , due to an assumption that $\mathrm{VO}_{2}$ measurements outside the range $17-40 \mathrm{~mL} / \mathrm{min} / \mathrm{kg}$ would be extremely unlikely. In the IBM group, however, 10 of the 17 participants had baseline $\mathrm{VO}_{2}$ measures below $17 \mathrm{~mL} / \mathrm{min} / \mathrm{kg}$ and the group mean was $14.5 \mathrm{~mL} / \mathrm{min} / \mathrm{kg}$. This may have been due to their older age and potential greater predisposition to sedentary lifestyles. Although the CMT group presented as fitter at baseline, 3 participants were also below the $17 \mathrm{~mL} / \mathrm{min} / \mathrm{kg}$ threshold. This may have influenced the effect sizes in this study, especially with the small sample, and must be considered when estimating the sample size of a phase 3 trial. A key aim for future training trials in IBM will be to see if $\mathrm{VO}_{2}$ peak can be increased to greater than or equal to $17.9 \mathrm{~mL} / \mathrm{min} / \mathrm{kg}$, the threshold for independent community living in older adults. ${ }^{24}$

The improvement in work rate showed similar magnitudes of change as $\mathrm{VO}_{2}$ peak, but none of the other secondary measures showed consistent group changes with the training or control interventions. The sample size in this study was likely to be insufficient to show change in some of the functional measures, but it may also be because the exercise intervention did not specifically train leg strength or walking. Larger 
Table 5 Summary of themes from qualitative interviews with 46 participants

\begin{tabular}{|c|c|}
\hline Main themes & Feedback \\
\hline \multirow[t]{2}{*}{$\begin{array}{l}\text { Reasons for } \\
\text { participating }\end{array}$} & $\begin{array}{l}\text { Most participants were expecting to participate in the trial to learn about their conditions and be able to achieve physical } \\
\text { benefits. }\end{array}$ \\
\hline & Most participants offered altruistic motives for participation. \\
\hline \multirow{2}{*}{$\begin{array}{l}\text { Expectations of } \\
\text { participating }\end{array}$} & Participants expected physical gains from their participation. \\
\hline & $\begin{array}{l}\text { Almost all participants felt that exercising regularly would help their condition and that any improvement would lead to } \\
\text { a positive state of well-being. }\end{array}$ \\
\hline \multirow[t]{2}{*}{ Experience of trial } & Most participants described their experiences of the trial as "just fine." \\
\hline & Some participants experienced physical difficulties during the trial. \\
\hline \multirow[t]{4}{*}{ Support } & Participants expressed their positive feelings towards the level of support received. \\
\hline & Families and friends were very supportive of their participation. \\
\hline & All participants described their gym instructors as likeable and helpful professionals. \\
\hline & Participants regarded a free gym membership as a requirement for them to carry on exercising after the trial. \\
\hline \multirow[t]{3}{*}{ Outcomes of exercise } & $\begin{array}{l}\text { Most participants who expressed positive outcomes from their participation did so regarding their level of fitness. These } \\
\text { participants felt fitter. }\end{array}$ \\
\hline & Most participants had observed a positive effect on their well-being as a consequence of participating. \\
\hline & $\begin{array}{l}\text { Many participants highlighted the positive effect of the exercise on their well-being and mood; some participants specifically } \\
\text { mentioned positive psychological effects while others commented that more psychological support is needed. }\end{array}$ \\
\hline
\end{tabular}

samples may also be required to ascertain the effect on some of the nonmotoric factors, such as mood, fatigue, self-efficacy, and sleep. There are no studies to date that relate these factors to aerobic capacity in CMT or IBM.

There were limitations and challenges encountered during this trial that must be considered in the design of a phase 3 study. Recruitment of these rare conditions was a factor, particularly in IBM, where potential recruits tended to have more comorbidity and did not pass the safety screening for maximal exercise testing. To overcome this problem, submaximal exercise tests could be used in a phase 3 trial to reduce risk to the patient and thus increase the recruitment pool and provide a more representative sample of patient populations. Gas exchange threshold and oxygen uptake kinetic variables are ideal candidates for future studies as they are derived from submaximal exercise tests, have been successfully utilized as a markers of fitness in many clinical populations, and are responsive to exercise training. ${ }^{25,26}$

The crossover design was also a challenge in 2 ways. First, people were put off by the prospect of detraining if they were in the group that exercised first. This affected recruitment. In the CMT group, the $\mathrm{VO}_{2}$ peak did not fully return to baseline after the 8-week washout period. This will have influenced the group means and the effect sizes. If some of the recruitment challenges are addressed with a multicenter phase 3 trial and submaximal testing, a more traditional 2-arm design will be possible and would be preferable to a crossover trial.
To date, this is the largest study of aerobic exercise training in people with CMT and IBM. The protocol was conducted in community leisure facilities and demonstrated that a standard aerobic training program using a bicycle ergometer is feasible, well-tolerated, and safe for people with CMT and IBM. The prescribed program had an effect on cardiopulmonary exercise capacity and efficacy will require investigation in larger trials. Consideration must also be given to the degree of motivational and financial support required for people with NMDs to exercise on a longer-term basis as part of a selfmanagement strategy.

\section{Study funding}

This work was funded by an NIHR Research for Patient Benefit Award PB-PG-0711-25151 (Chief Investigator: G.M.R.). This is a summary of independent research funded by the National Institute for Health Research (NIHR)'s Research for Patient Benefit Program. The views expressed are those of the authors and not necessarily those of the NHS, the NIHR, or the Department of Health. The Queen Square MRC Centre for Neuromuscular Diseases is supported by a Medical Research Council grant (MR/K000608/1) (M.G.H., M.M.R., P.M.M., G.M.R.). M.M.R. received support from Medical Research Council (MRC), MRC Centre grant (G0601943), and the National Institutes of Neurological Diseases and Stroke and office of Rare Diseases (U54NS065712). This research was also supported by the National Institute for Health Research University College London Hospitals Biomedical Research Centre. 


\section{Disclosure}

The authors report no disclosures relevant to the manuscript. Go to Neurology.org/N for full disclosures.

\section{Publication history}

Received by Neurology August 10, 2018. Accepted in final form December 11, 2018.

Appendix Authors

\begin{tabular}{|c|c|c|c|}
\hline Name & Location & Role & Contribution \\
\hline $\begin{array}{l}\text { Amanda } \\
\text { Wallace, PhD }\end{array}$ & $\begin{array}{l}\text { Queen Square, } \\
\text { London, UK }\end{array}$ & Author & $\begin{array}{l}\text { Primary trial } \\
\text { coordinator, data } \\
\text { management, } \\
\text { designed and } \\
\text { conceptualized } \\
\text { study, reviewed } \\
\text { manuscript for } \\
\text { intellectual } \\
\text { content }\end{array}$ \\
\hline $\begin{array}{l}\text { Alexandra } \\
\text { Pietrusz, BSc }\end{array}$ & $\begin{array}{l}\text { Queen Square, } \\
\text { London, UK }\end{array}$ & Author & $\begin{array}{l}\text { Delivered } \\
\text { intervention, } \\
\text { reviewed } \\
\text { manuscript for } \\
\text { intellectual } \\
\text { content }\end{array}$ \\
\hline $\begin{array}{l}\text { Elizabeth } \\
\text { Dewar, BSc }\end{array}$ & $\begin{array}{l}\text { Queen Square, } \\
\text { London, UK }\end{array}$ & Author & $\begin{array}{l}\text { Major } \\
\text { contributor to } \\
\text { data collection, } \\
\text { reviewed } \\
\text { manuscript for } \\
\text { intellectual } \\
\text { content }\end{array}$ \\
\hline $\begin{array}{l}\text { Magdalena } \\
\text { Dudziec, BSc }\end{array}$ & $\begin{array}{l}\text { Queen Square, } \\
\text { London; and } \\
\text { Kingston/St } \\
\text { George's } \\
\text { University of } \\
\text { London, UK }\end{array}$ & Author & $\begin{array}{l}\text { Major } \\
\text { contributor to } \\
\text { data collection, } \\
\text { reviewed } \\
\text { manuscript for } \\
\text { intellectual } \\
\text { content }\end{array}$ \\
\hline $\begin{array}{l}\text { Katherine } \\
\text { Jones, PhD }\end{array}$ & $\begin{array}{l}\text { Queen Square, } \\
\text { London, UK }\end{array}$ & Author & $\begin{array}{l}\text { Secondary trial } \\
\text { coordinator, data } \\
\text { management, } \\
\text { reviewed } \\
\text { manuscript for } \\
\text { intellectual } \\
\text { content }\end{array}$ \\
\hline $\begin{array}{l}\text { Philip Hennis, } \\
\text { PhD }\end{array}$ & UCL, London, UK & Author & $\begin{array}{l}\text { Training, } \\
\text { contributor to } \\
\text { data collection } \\
\text { and analysis, } \\
\text { interpretation of } \\
\text { data }\end{array}$ \\
\hline $\begin{array}{l}\text { Annette Sterr, } \\
\text { PhD }\end{array}$ & $\begin{array}{l}\text { University of } \\
\text { Surrey, } \\
\text { Guildford, UK }\end{array}$ & Author & $\begin{array}{l}\text { Qualitative data } \\
\text { collection, } \\
\text { analysis and } \\
\text { interpretation }\end{array}$ \\
\hline $\begin{array}{l}\text { Gianluca Baio, } \\
\text { PhD }\end{array}$ & UCL, London, UK & Author & $\begin{array}{l}\text { Quantitative data } \\
\text { analysis and } \\
\text { interpretation }\end{array}$ \\
\hline $\begin{array}{l}\text { Pedro } \\
\text { Machado, MD, } \\
\text { PhD }\end{array}$ & $\begin{array}{l}\text { Queen Square, } \\
\text { London, UK }\end{array}$ & Author & $\begin{array}{l}\text { Assistance with } \\
\text { data collection, } \\
\text { reviewed } \\
\text { manuscript for } \\
\text { intellectual } \\
\text { content }\end{array}$ \\
\hline
\end{tabular}

Appendix (continued)

\begin{tabular}{|c|c|c|c|}
\hline Name & Location & Role & Contribution \\
\hline $\begin{array}{l}\text { Matilde Laurá, } \\
\text { MD, PhD }\end{array}$ & $\begin{array}{l}\text { Queen Square, } \\
\text { London, UK }\end{array}$ & Author & $\begin{array}{l}\text { Assistance with } \\
\text { data collection, } \\
\text { reviewed } \\
\text { manuscript for } \\
\text { intellectual } \\
\text { content }\end{array}$ \\
\hline
\end{tabular}

\begin{tabular}{|c|c|c|c|}
\hline $\begin{array}{l}\text { Iwona } \\
\text { Skorupinska, } \\
\text { BSc }\end{array}$ & $\begin{array}{l}\text { Queen Square, } \\
\text { London, UK }\end{array}$ & Author & $\begin{array}{l}\text { Recruitment, } \\
\text { assistance with } \\
\text { data collection }\end{array}$ \\
\hline $\begin{array}{l}\text { Mariola } \\
\text { Skorunpinska, } \\
\text { MSc }\end{array}$ & $\begin{array}{l}\text { Queen Square, } \\
\text { London, UK }\end{array}$ & Author & $\begin{array}{l}\text { Recruitment, } \\
\text { assistance with } \\
\text { data collection }\end{array}$ \\
\hline Karen Butcher & $\begin{array}{l}\text { CMTUK charity, } \\
\text { Dorset, UK }\end{array}$ & Collaborator & $\begin{array}{l}\text { Patient } \\
\text { representative } \\
\text { involved in } \\
\text { review of design } \\
\text { and participant } \\
\text { materials }\end{array}$ \\
\hline $\begin{array}{l}\text { Michael } \\
\text { Trenell, PhD }\end{array}$ & $\begin{array}{l}\text { Newcastle } \\
\text { University, } \\
\text { Newcastle, UK }\end{array}$ & Author & $\begin{array}{l}\text { Design of study, } \\
\text { exercise } \\
\text { physiology } \\
\text { support }\end{array}$ \\
\hline $\begin{array}{l}\text { Mary M. Reilly, } \\
\text { MD }\end{array}$ & $\begin{array}{l}\text { Queen Square, } \\
\text { London, UK }\end{array}$ & Author & $\begin{array}{l}\text { Designed and } \\
\text { conceptualized } \\
\text { study, reviewed } \\
\text { manuscript for } \\
\text { intellectual } \\
\text { content }\end{array}$ \\
\hline $\begin{array}{l}\text { Michael G. } \\
\text { Hanna, } \\
\text { BMBCh, MD }\end{array}$ & $\begin{array}{l}\text { Queen Square, } \\
\text { London, UK }\end{array}$ & Author & $\begin{array}{l}\text { Sponsorship, } \\
\text { designed and } \\
\text { conceptualized } \\
\text { study, reviewed } \\
\text { manuscript for } \\
\text { intellectual } \\
\text { content }\end{array}$ \\
\hline $\begin{array}{l}\text { Gita M. } \\
\text { Ramdharry, } \\
\text { PhD }\end{array}$ & $\begin{array}{l}\text { Queen Square, } \\
\text { London; and } \\
\text { Kingston/St } \\
\text { George's } \\
\text { University of } \\
\text { London, UK }\end{array}$ & Author & $\begin{array}{l}\text { Chief } \\
\text { investigator, } \\
\text { designed and } \\
\text { conceptualized } \\
\text { study, data } \\
\text { management, } \\
\text { analysis and } \\
\text { interpretation, } \\
\text { preparation of } \\
\text { manuscript }\end{array}$ \\
\hline
\end{tabular}

\section{References}

1. Ramdharry GM, Pollard AJ, Grant R, et al. A study of physical activity comparing people with Charcot-Marie-Tooth disease to normal control subjects. Disabil Rehabil 2017;39:1753-1758.

2. Anens E, Emtner M, Hellström K. Exploratory study of physical activity in persons with Charcot-Marie-Tooth disease. Arch Phys Med Rehabil 2015;96: 260-268.

3. Kalkman JS, Schillings ML, Zwarts MJ, van Engelen BG, Bleijenberg G. The development of a model of fatigue in neuromuscular disorders: a longitudinal study. J Psychosom Res 2007;62:571-579.

4. Carter GT, Abresch RT, Fowler WMJ, Johnson ER, Kilmer DD, McDonald CM. Profiles of neuromuscular diseases: hereditary motor and sensory neuropathy, types I and II. Am J Phys Med Rehabil 1995;74:S140-S149.

5. Wiesinger GF, Quittan M, Nuhr M, Volc-Platzer G, Zehetgruber M, Graninger W. Aerobic capacity in adult dermatomyositis/polymyositis patients and healthy controls. Arch Phys Med Rehabil 2000;81:1-5.

6. Johnson LG, Edwards DJ, Walters S, Thickbroom GW, Mastaglia FL. The effectiveness of an individualized, home-based functional exercise program for patients with sporadic inclusion body myositis. J Clin Neuromuscul Dis 2007;8:187.

7. Johnson LG, Collier KE, Edwards DJ, et al. Improvement in aerobic capacity after an exercise program in sporadic inclusion body myositis. J Clin Neuromuscul Dis 2009; 10:178-184. 
8. El Mhandi L, Millet GY, Calmels P, Richard R, Gautheron V, Féasson L. Benefits of interval-training on fatigue and functional capacities in Charcot-Marie-Tooth disease. Muscle Nerve 2008;37:601-610.

9. Elsworth C, Winward C, Sackley C, et al. Supported community exercise in people with long-term neurological conditions: a phase II randomized controlled trial. Clin Rehabil 2011;25:588-598.

10. Kilmer DD. Response to aerobic exercise training in humans with neuromuscular disease. Am J Phys Med Rehabil 2002;81:S148-S150.

11. Ramdharry GM, Pollard A, Anderson C, et al. A pilot study of proximal strength training in Charcot-Marie-Tooth disease: Ramdharry. J Peripher Nerv Syst 2014;19:328-332.

12. Mora-Rodriguez R, Ortega JF, Hamouti N, et al. Time-course effects of aerobic interval training and detraining in patients with metabolic syndrome. Nutr Metab Cardiovasc Dis 2014;24:792-798.

13. Lovell DI, Cuneo R, Wallace J, McLellan C. The hormonal response of older men to submaximum aerobic exercise: the effect of training and detraining. Steroids 2012;77:413-418.

14. Jeppesen TD, Schwartz M, Olsen DB, et al. Aerobic training is safe and improves exercise capacity in patients with mitochondrial myopathy. Brain J Neurol 2006;129: 3402-3412.

15. Shy ME, Blake J, Krajewski K, et al. Reliability and validity of the CMT neuropathy score as a measure of disability. Neurology 2005;64:1209-1214.

16. Jackson CE, Barohn RJ, Gronseth G, Pandya S, Herbelin L. The Muscle Study Group (MSG): inclusion body myositis functional rating scale: a reliable and valid measure of disease severity. Muscle Nerve 2008;37:473-476.

17. American College of Sports Medicine. ACSM's Guidelines for Exercise Testing and Prescription. 8th ed. Baltimore: Lippincott Williams \& Wilkins; 2009.
18. Lai B, Kim Y, Wilroy J, Bickel CS, Rimmer JH, Motl RW. Sustainability of exercise intervention outcomes among people with disabilities: a secondary review. Disabil Rehabil 2018;0:1-12.

19. Quinn L, Hamana K, Kelson M, et al. A randomized, controlled trial of a multi-modal exercise intervention in Huntington's disease. Parkinsonism Relat Disord2016;31: $46-52$.

20. Mulligan HF, Hale LA, Whitehead L, Baxter GD. Barriers to physical activity for people with long-term neurological conditions: a review study. Adapt Phys Act $\mathrm{Q}$ 2012;29:243-265.

21. Dunn A, Marsden DL, Barker D, Van Vliet P, Spratt NJ, Callister R. Cardiorespiratory fitness and walking endurance improvements after 12 months of an individualised home and community-based exercise programme for people after stroke. Brain Inj 2017;31:1617-1624.

22. Platta ME, Ensari I, Motl RW, Pilutti LA. Effect of exercise training on fitness in multiple sclerosis: a meta-analysis. Arch Phys Med Rehabil 2016;97:1564-1572.

23. Pang MY, Eng JJ, Dawson AS, Gylfadóttir S. The use of aerobic exercise training in improving aerobic capacity in individuals with stroke: a meta-analysis. Clin Rehabil 2006;20:97-111.

24. Paterson DH, Govindasamy D, Vidmar M, Cunningham DA, Koval JJ. Longitudinal study of determinants of dependence in an elderly population. J Am Geriatr Soc 2004; 52:1632-1638.

25. Poole DC, Jones AM. Oxygen uptake kinetics. Compr Physiol 2012;2:933-996.

26. Wasserman K. Principles of Exercise Testing and Interpretation: Including Pathophysiology and Clinical Applications. Baltimore: Wolters Kluwer Health/Lippincott Williams \& Wilkins; 2012. 


\section{Neurology}

\section{Community exercise is feasible for neuromuscular diseases and can improve aerobic capacity}

Amanda Wallace, Aleksandra Pietrusz, Elizabeth Dewar, et al.

Neurology 2019;92;e1773-e1785 Published Online before print March 8, 2019

DOI 10.1212/WNL.0000000000007265

\section{This information is current as of March 8, 2019}

\section{Updated Information \&} Services

References

Subspecialty Collections

Permissions \& Licensing

Reprints including high resolution figures, can be found at: http://n.neurology.org/content/92/15/e1773.full

This article cites 24 articles, 1 of which you can access for free at: http://n.neurology.org/content/92/15/e1773.full\#ref-list-1

This article, along with others on similar topics, appears in the following collection(s):

\section{All Rehabilitation}

http://n.neurology.org/cgi/collection/all_rehabilitation

Clinical trials Randomized controlled (CONSORT agreement)

http://n.neurology.org/cgi/collection/clinical_trials_randomized_contro lled_consort_agreement

Muscle disease

http://n.neurology.org/cgi/collection/muscle_disease

Peripheral neuropathy

http://n.neurology.org/cgi/collection/peripheral_neuropathy

Information about reproducing this article in parts (figures,tables) or in its entirety can be found online at:

http://www.neurology.org/about/about_the_journal\#permissions

Information about ordering reprints can be found online:

http://n.neurology.org/subscribers/advertise

Neurology ${ }^{\circledR}$ is the official journal of the American Academy of Neurology. Published continuously since 1951, it is now a weekly with 48 issues per year. Copyright Copyright ( 2019 The Author(s). Published by Wolters Kluwer Health, Inc. on behalf of the American Academy of Neurology.. All rights reserved. Print ISSN: 0028-3878. Online ISSN: 1526-632X.

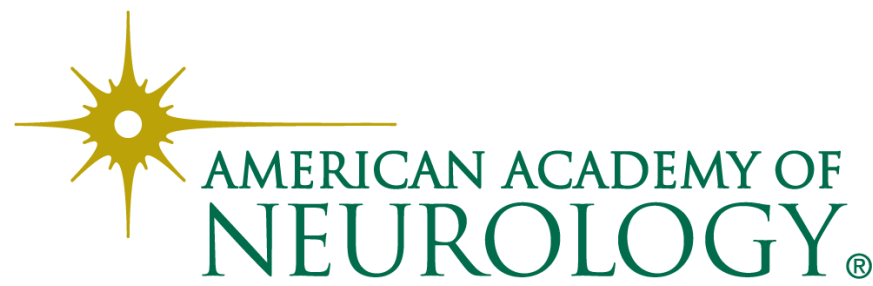

